\title{
Integração do QFD e da FMEA por meio de uma sistemática para tomada de decisões no processo de desenvolvimento de produtos
}

\author{
Alejandro Germán Frank ${ }^{\mathrm{a}^{*}}$, Danilo Cuzzuol Pedrini ${ }^{\mathrm{b}}$, \\ Márcia Elisa Echevestec ${ }^{c}$, José Luis Duarte Ribeiro ${ }^{d}$ \\ a*frank@producao.ufrgs.br, UFRGS, Brasil \\ bdanilocp@petrobras.com.br, Petrobras, Brasil \\ 'echeveste@producao.ufrgs.br, UFRGS, Brasil \\ dribeiro@producao.ufrgs.br, UFRGS, Brasil
}

\begin{abstract}
Resumo
Este artigo apresenta uma sistemática que orienta as ações a serem tomadas no processo de desenvolvimento de produtos (PDP) quanto ao atendimento da qualidade e confiabilidade. A sistemática foi desenvolvida por meio de uma pesquisa-ação e propõe a integração do QFD e da FMEA, permitindo decidir quais características da qualidade e confiabilidade são prioritárias para o desenvolvimento dos componentes do produto. A proposta traz duas contribuições: (i) uma modificação na avaliação dos indicadores de risco da FMEA, reduzindo a subjetividade de atribuição dos valores, e (ii) a integração desses indicadores e dos índices de priorização obtidos das matrizes do QFD em um diagrama de decisões para o desenvolvimento dos componentes. Esse diagrama permite visualizar o impacto de cada componente sobre as características de qualidade e confiabilidade de maneira conjunta, facilitando a tomada de decisões no desenvolvimento do produto. Os resultados práticos destacaram a sua facilidade de aplicação.
\end{abstract}

Palavras-chave

QFD. FMEA. Qualidade. Confiabilidade. Desenvolvimento de produto.

\section{Introdução}

No processo de desenvolvimento de produtos (PDP) devem ser consideradas duas características essenciais para atender o mercado: a qualidade e a confiabilidade do produto. Enquanto a primeira atende às necessidades e demandas do cliente, a segunda atende às questões de continuidade das características iniciais projetadas no produto ao longo do seu ciclo de vida, evitando falhas e riscos que afetem a segurança do produto projetado. Ambas as características devem ser estudadas já no projeto inicial dos componentes do produto, ajudando assim a economizar tempo e custos do projeto (PICKARD; DIETER, 2008). A fim de dar suporte ao PDP para atingir esses objetivos, diversos métodos e técnicas têm sido aplicados. Dentre eles destacam-se o desdobramento da função qualidade (Quality Function Deployment - QFD), para o atendimento à qualidade, e a análise de modo e efeito de falhas (Failure Mode and Effect Analysis - FMEA), para o atendimento à prevenção de falhas e confiabilidade. De acordo com Ginn et al. (1998) e Fernandes e Rebelato (2006), ambas as ferramentas visam melhorar a percepção do cliente em relação às funções do produto, agindo de forma complementar: o QFD busca consolidar ou melhorar as características dos produtos para atender aos requisitos do cliente, já a FMEA concentra-se na prevenção de falhas do produto, mantendo suas funções básicas e atingindo um nível esperado de qualidade e, assim, evitando a insatisfação do cliente.

Segundo Fernandes e Rebelato (2006), o QFD e a FMEA são frequentemente vistos como ferramentas sem inter-relação e sua integração, quando ocorre na prática, é tradicionalmente insuficiente e mal explorada, não sendo aproveitado todo o potencial que essas técnicas teriam se aplicadas conjuntamente da maneira correta. Essa falta de integração pode ser compreendida pelo 
fato de essas ferramentas terem sido desenvolvidas independentemente, por diferentes especialistas, para atingir objetivos específicos em contextos distintos. Consequentemente, não tinham sido previstas inicialmente interfaces para sua aplicação conjunta (GINN et al., 1998; FERNANDES; REBELATO, 2006).

Algumas pesquisas como as de Ginn et al. (1998), Tan (2003), Rosa (2005), Fernandes e Rebelato (2006), Frank, Pedrini e Echeveste (2008), Tanik (2010), entre outros, têm destacado que o QFD e a FMEA poderiam ser relacionados e utilizados de forma complementar. Porém, alguns desses trabalhos consideram apenas uma sequência de etapas para a utilização de ambas as ferramentas, sem estabelecer de fato uma integração propriamente dita entre elas. Em outros casos, a integração proposta não considera toda a complexidade das características de qualidade e confiabilidade envolvidas nessa integração.

Considerando o acima exposto, o objetivo deste artigo é propor uma sistemática que oriente as ações a serem tomadas no PDP através da integração do QFD e da FMEA, permitindo assim decidir quais características de qualidade e confiabilidade priorizar durante o desenvolvimento dos componentes do produto. 0 foco desta proposta é, além da integração entre ambas as ferramentas, a praticidade de utilização da sistemática, de maneira a torná-la útil para as empresas. Para atingir esse objetivo, este trabalho usa a abordagem de FMEA considerando os custos de reparo como severidade da falha, conforme abordada por autores como Gilchrist (1993) e Ahsen (2008), gerando, por fim, um índice para cada componente. 0 resultado obtido na FMEA é integrado aos índices de priorização da matriz do produto do QFD, por meio de um diagrama de decisão para o desenvolvimento dos componentes do produto. Após o desenvolvimento teórico da sistemática proposta, a mesma foi ajustada por meio de uma pesquisa-ação em uma empresa desenvolvedora de condicionadores de ar. Os resultados obtidos são também discutidos.

Basicamente, o presente trabalho é dividido nas seguintes grandes partes: 2. Referencial teórico; 3. Método de pesquisa; 4. Sistemática de integração proposta; 5. Avaliação prática da proposta; 6. Discussões; e 7. Considerações finais.

\section{Referencial teórico}

\subsection{Desdobramento da função qualidade (QFD)}

O QFD é uma ferramenta que traduz sistematicamente as necessidades dos clientes em requisitos técnicos para o desenvolvimento de produtos, podendo ser considerada um guia a ser utilizado ao longo das fases de concepção, criação e produção de novos produtos ou serviços (AKAO, 1988; MIGUEL, 2005; MEHRJERDI, 2010). Segundo Carnevalli e Miguel (2007) e Carnevalli, Sassi e Miguel (2004), nos últimos anos, a maior parte das pesquisas em QFD focou principalmente aspectos conceituais, buscando adaptar essa ferramenta a aplicações específicas ou melhorá-la, de modo a facilitar a sua aplicação. Atualmente, o QFD permite aplicações em diferentes contextos, como no desenvolvimento de novos produtos, na associação das demandas do mercado e em especificações de projeto e de processo, conforme nos estudos de Dikmen, Birgonul e Kiziltas (2005) e Marsot (2005). Também funciona como uma ferramenta de apoio a decisões gerenciais no entendimento do que é importante e crítico segundo a percepção do cliente ou usuário, conforme os trabalhos de Killen, Walker e Hunt (2005), LePrevost e Mazur (2005) e Bosh e Enríquez (2005). Por outro lado, Mehrjerdi (2010) destaca as interações do QFD com diferentes metodologias e ferramentas, como: método de análise hierárquica (AHP), método de análise de rede (ANP), lógica difusa (fuzzy), teoria de solução inventiva de problemas (TRIZ), gestão da qualidade total (TQM), controle estatístico de processos (CEP) e projeto de experimentos, entre outras técnicas.

0 modelo conceitual tradicional mais conhecido do QFD é o modelo de quatro fases, que contempla as seguintes matrizes: (i) a matriz da qualidade; (ii) matriz do produto; (iii) matriz de processos e (iv) matriz de recursos. Dessa forma, o QFD fornece o suporte para todas as fases de desenvolvimento de um novo produto, relacionando as demandas do consumidor com as especificações de engenharia e possibilitando o desdobramento até o projeto dos componentes do produto, incluída a definição das especificações das variáveis dos processos de produção bem como a alocação inicial de recursos operacionais (GOVERS, 1996; CHAN; WU, 2003; MEHRJERDI, 2010).

Neste artigo serão abordadas somente as matrizes de qualidade e matriz do produto, as quais estão relacionadas às fases iniciais do desenvolvimento do produto. Nessas fases utiliza-se primeiro a matriz da qualidade, que tem por finalidade traduzir as demandas identificadas junto ao cliente alvo em requisitos do cliente e, posteriormente, em características de qualidade do produto ou requisitos do produto. A seguir é utilizada a matriz do produto que indica quais são os componentes do produto mais importantes para atender as características da qualidade e, consequentemente, para o atendimento da qualidade demandada (CHENG; MELO FILHO, 2007). 0 procedimento para a construção de ambas as matrizes da qualidade será explicado posteriormente, na apresentação da sistemática proposta. 


\subsection{Análise do modo e efeitos de falhas (FMEA)}

Gilchrist (1993) define a FMEA como uma ferramenta utilizada para identificar, priorizar e eliminar falhas, problemas e erros potenciais em produtos ou sistemas em desenvolvimento antes do seu lançamento no mercado. 0 resultado da aplicação da FMEA é a quantificação dos riscos de falha baseada na criticidade de cada modo de falha, provendo uma priorização de modos de falha e uma lista de ações preventivas para seu controle e remoção. Essa ferramenta apresenta um caráter preditivo de falhas e pode ser aplicada ainda na fase de desenvolvimento do produto e fases de projeto, de forma a diminuir a frequência de ocorrências e melhorar a eficiência na detecção das possíveis falhas, diminuindo a necessidade de retrabalho em estágios posteriores de produção (FRANCESCHINI; GALETTO, 2001; TAN, 2003; SHAHIN, 2004).

Segundo Fernandes e Rebelato (2006), a FMEA pode ser aplicada ao sistema, ao produto ou ao processo. Sua aplicação ao produto permite definir a necessidade de alterações no projeto do produto ainda em suas fases iniciais, estabelecer prioridades para as ações de melhoria, auxiliar na definição de testes e validação do produto, na identificação de características críticas e na avaliação dos requisitos e alternativas do projeto.

0 procedimento geral da FMEA requer a execução das seguintes etapas: (i) identificação de modos de falha conhecidos e potenciais do produto; (ii) identificação dos efeitos e da severidade de cada modo de falha do produto; (iii) identificação das possiveis causas e probabilidades de ocorrência para cada modo de falha; (iv) identificação dos modos de falha e sua probabilidade de detecção; e (v) avaliação do potencial de risco de cada modo de falha e definição de medidas para sua eliminação ou redução. A avaliação e priorização de cada modo de falha são definidas através de três índices: (i) índice de ocorrência (0), associado à probabilidade de ocorrência de um determinado modo de falha e causa; (ii) índice de severidade (S), que indica a gravidade dos efeitos provenientes de um modo de falha; e (iii) índice de detecção (D), associado à probabilidade de detectar o modo de falha antes que ele chegue ao cliente, através de revisões de projeto, testes, medidas de controle de qualidade ou até mesmo por meio de medidas que previnam o uso indevido do produto por parte do usuário. 0 produto desses três índices permite obter um índice de risco de cada modo de falha (PUENTE et al., 2001; SHAHIN, 2004; AHSEN, 2008). Esse índice possibilita determinar-se a ordem de priorização das $j$ falhas para os $i$ componentes do produto, de forma que mecanismos de controle sejam estabelecidos para evitar a sua ocorrência. 0 procedimento para a construção da FMEA será explicado na apresentação da sistemática proposta.

\subsection{Métodos existentes para a integração entre QFD e FMEA}

Segundo Tan (2003), o uso isolado do QFD pode gerar um produto muito atrativo ao cliente, porém sem confiabilidade para o exercício de todas as suas funções. Por outro lado, o uso isolado da FMEA pode gerar um produto extremamente confiável, mas que pode não considerar características atrativas ao cliente. Dessa forma, encontram-se na literatura diversos métodos de integração entre QFD e FMEA para o projeto de produto, entre os quais podem-se destacar cinco propostas, apresentas a seguir.

Yang e Kapur (1997) propuseram um modelo conceitual de integração entre QFD e FMEA (Figura 1). A proposta consiste em incluir as exigências de confiabilidade priorizadas pelo cliente como itens de qualidade demandados da matriz de qualidade do QFD, transformando-as em especificações de engenharia que são utilizadas como entrada para a FMEA. Assim, o efeito de cada falha é relacionado com a correspondente especificação de engenharia, permitindo obter uma especificação otimizada de confiabilidade. Contudo, Braglia, Fantoni e Frosolini (2007) e Tan (2003) afirmam que essa proposta permanece teórica, já que não revela como os clientes priorizariam as possíveis falhas e como a priorização do QFD seria incorporada à FMEA.

Braglia, Fantoni e Frosolini (2007) adaptaram o QFD, propondo uma "casa da confiabilidade", onde são priorizadas as possíveis falhas do produto segundo a opinião dos clientes e onde, posteriormente, ocorre priorização das possíveis soluções para essas falhas, com base nos custos de cada solução. Contudo, esta proposta utiliza apenas a estrutura do QFD, não analisa

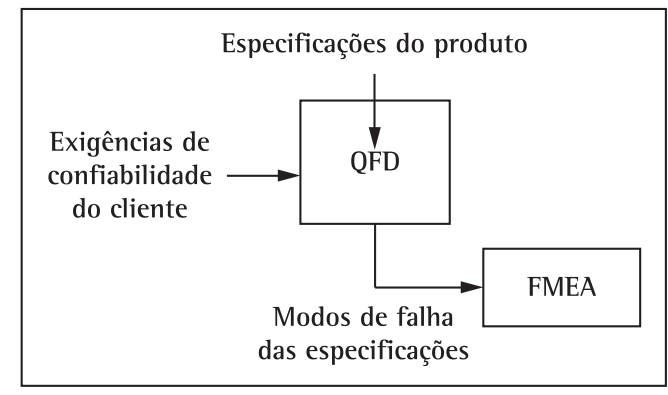

Figura 1. Integração entre QFD e FMEA proposta por Yang e Kapur (1997). 
as características da qualidade demandada pelos clientes. Portanto, não é considerado um método de integração entre qualidade e confiabilidade. Tan (2003), por sua vez, propôs um método de confiabilidade focado no cliente, baseado na integração entre QFD e FMEA (Figura 2). Esse método consiste em utilizar duas matrizes QFD para priorizar os requisitos do produto: a matriz funcional da qualidade, que traduz os efeitos de falhas, na voz do cliente externo, em requisitos técnicos dos produtos e a matriz da confiabilidade, que prioriza as possíveis partes defeituosas causadoras de modos de falha apontadas por clientes internos. A seguir, utiliza-se uma FMEA modificada com a inclusão de dois novos índices: 0 índice de importância (l) e o índice de criticidade (C). Com o uso da matriz da confiabilidade obtém-se o índice 1, através da priorização dos modos de falha apresentados pelo cliente interno. Já o índice C é obtido através da matriz funcional da qualidade, sendo calculado pela priorização dos efeitos da falha apontados pelos clientes externos em relação aos requisitos técnicos do produto. Os demais índices da FMEA (S, 0 e D) são obtidos da mesma forma que na FMEA tradicional.

Na proposta de Cheng e Melo Filho (2007), apresentada na Figura 3, as priorizações dos componentes resultantes do QFD são utilizadas para avaliar quais componentes do produto são mais importantes no atendimento às necessidades do cliente. A partir dessa priorização realiza-se a FMEA tradicional para cada um dos componentes mais representativos da ponderação obtida no QFD. Essa proposta utiliza o QFD e a FMEA em forma sequencial, sendo que o QFD auxilia a FMEA na seleção dos componentes a serem avaliados. No uso da FMEA, conforme Cheng e Melo Filho (2007), os

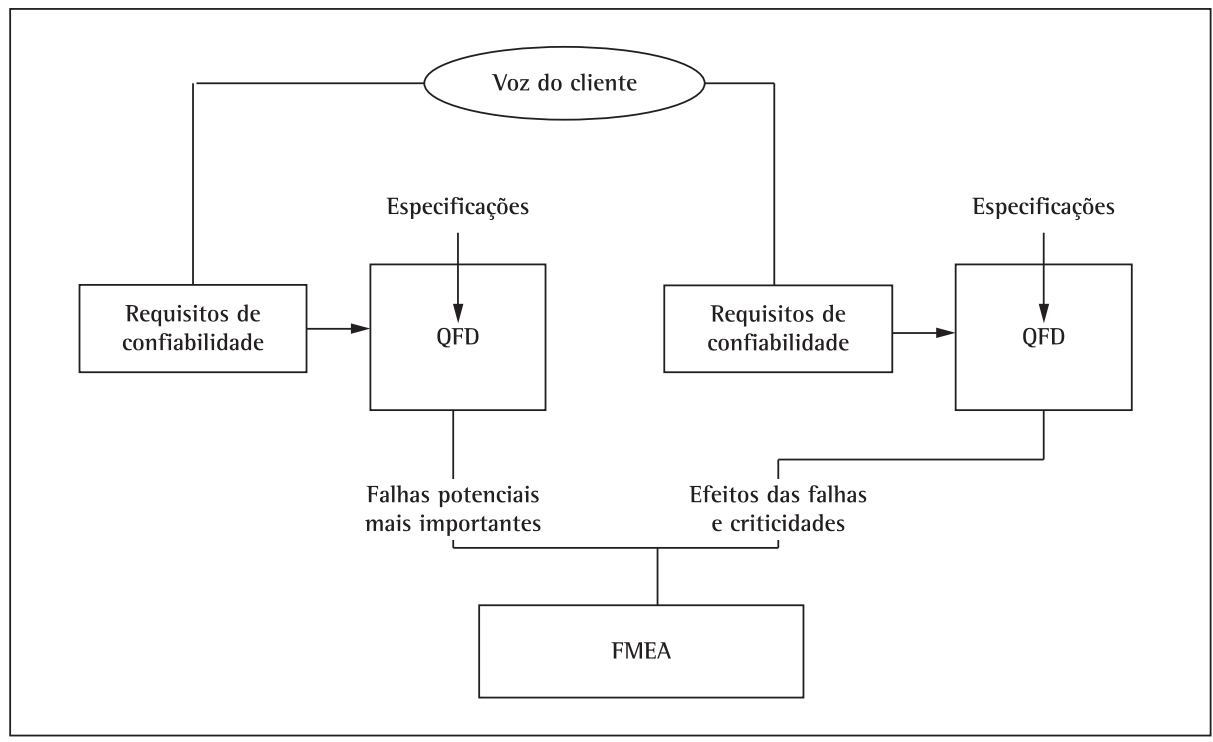

Figura 2. Integração entre QFD e FMEA proposta por Tan (2003).

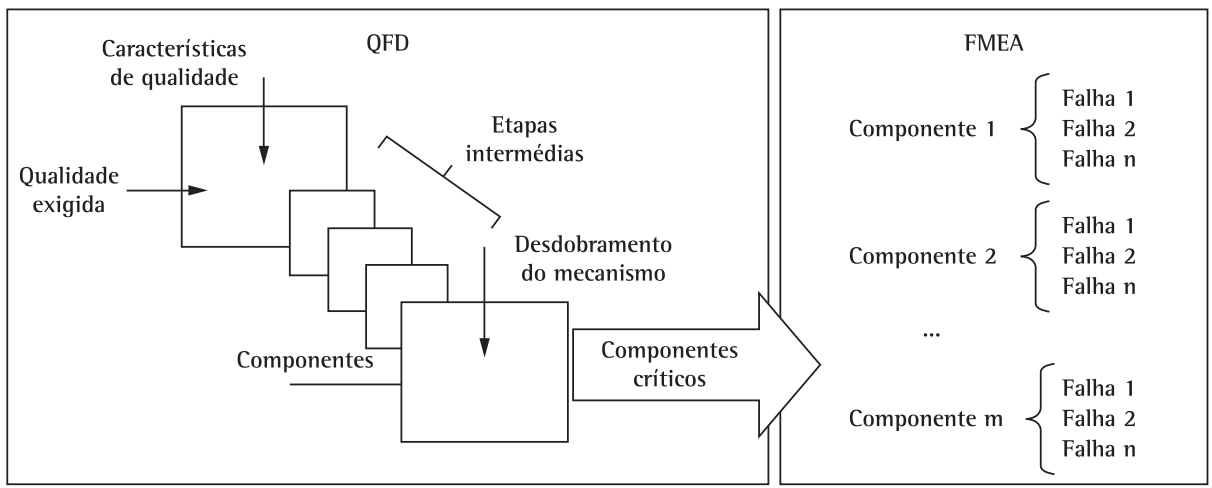

Figura 3. Integração entre QFD e FMEA proposta por Cheng e Melo Filho (2007). 
componentes são desdobrados nas possíveis falhas, as quais são avaliadas pelos indicadores tradicionais dessa ferramenta. Finalmente, determina-se um ranking com as principais falhas de cada um dos componentes avaliados e que, portanto, devem ser objeto de revisões.

Uma lógica similar à proposta por Cheng e Melo Filho (2007) segue o método de Tanik (2010), apresentado na Figura 4. Nesse método primeiramente utiliza-se a matriz da qualidade do QFD na forma tradicional e, com base na expectativa do cliente, a equipe da FMEA identifica todas as falhas do produto que podem impedir o atendimento dos requisitos do cliente. A forma de integração entre essas duas ferramentas é dada através de uma matriz de correlação, na qual os modos de falha são listados nas linhas e as expectativas do cliente nas colunas. A seguir, preenche-se a intensidade de relação entre modos de falha e expectativas do cliente e, dessa forma, é possivel priorizar quais requisitos importantes do cliente estão mais ameaçados por diferentes modos de falha.

Por outro lado, na proposta de Fernandes e Rebelato (2006), apresentada na Figura 5, o QFD e a FMEA estão relacionadas através dos índices gerados após a aplicação das duas ferramentas, os quais

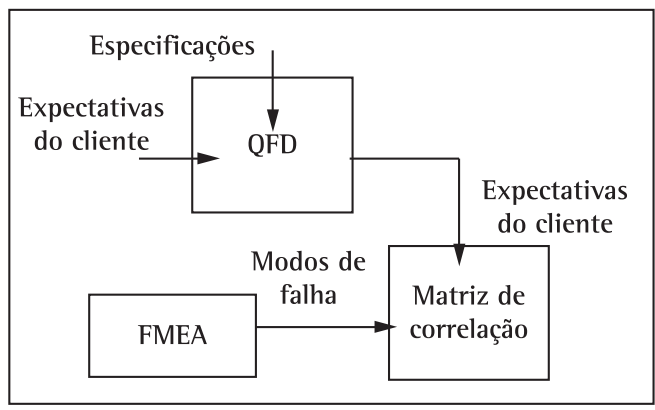

Figura 4. Integração entre QFD e FMEA proposta por Tanik (2010).

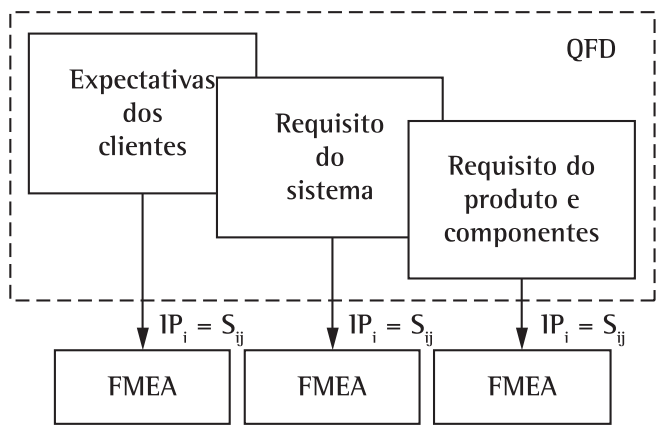

Figura 5. Integração entre QFD e FMEA proposta por Fernandes e Rebelato (2006). são utilizados de forma integrada. Nessa proposta, os valores resultantes dos índices de priorização de componentes (IP), obtidos da matriz QFD do produto, são utilizados como índices de severidade (S) da FMEA. Isso significa que, para a análise da FMEA, o grau de importância da falha será igual ao grau de importância do componente que pode falhar comparado à importância dos demais componentes do produto. Segundo Fernandes e Rebelato (2006), essa forma de integrar as duas ferramentas torna a avaliação de risco um indicador mais fidedigno do não atendimento das expectativas do produto se comparado à alternativa de realizar somente a avaliação baseada na experiência da equipe.

Posteriormente, Frank, Pedrini e Echeveste (2008) complementaram a proposta de Fernandes e Rebelato (2006) com um índice de risco modificado, o qual é obtido pela multiplicação do índice de risco padronizado da FMEA pelo índice de priorização dos componentes padronizado (IP) do QFD. A principal diferença conceitual entre esses dois trabalhos é que Frank, Pedrini e Echeveste (2008) consideram que os conceitos de qualidade demandada e confiabilidade são conceitos complementares e, dessa forma, o índice de severidade (S) que é apontado por um corpo técnico da equipe de desenvolvimento de produto não pode ser substituído pelo índice de priorização do componente (IP).

Nas propostas aqui apresentadas observa-se que quando considerados os itens do QFD na FMEA geralmente são incluídos apenas os mais importantes do ponto de vista da qualidade ou da confiabilidade, sem considerar simultaneamente ambos os critérios. lsso se deve à lógica sequencial da integração entre o QFD e a FMEA das sistemáticas apresentadas. Por outro lado, quando considerados ambos os critérios, são apenas incluídos alguns componentes e falhas, sem apresentar-se uma visão sistêmica das falhas e requisitos de qualidade de todos os componentes. Essas são algumas das limitações que a sistemática proposta busca contornar. Maiores detalhes das diferenças entre a proposta deste artigo e as sistemáticas existentes na literatura serão explicados na seção de discussões.

\section{Método de pesquisa}

Para a construção da sistemática proposta foi utilizado o método de pesquisa-ação, que consiste na implantação de uma ação por parte das pessoas ou grupos implicados no problema sob observação e no ajuste do problema através da participação ativa do pesquisador na realidade estudada (THIOLLENT, 2007; VAN DE VEN, 2007). Esse método foi escolhido por permitir desenvolver a sistemática proposta e ajustá-la através da avaliação prática. Para tanto, foram 
seguidos os passos metodológicos da pesquisa-ação propostos por Mello et al. (2012), descritos a seguir:

- a)Definição da estrutura teórico-conceitual: essa etapa consistiu na revisão da literatura e na construção teórica da sistemática, conforme apresentado nas seções 2 e 4.

- b)Seleção da unidade de análise: o caso prático para a análise da sistemática foi escolhido por conveniência. Trata-se de uma empresa que possui vínculos com a universidade dos pesquisadores e que se mostrou interessada em aplicar QFD-FMEA para a melhoria dos produtos desenvolvidos por ela. A aplicação é apresentada na seção 5 .

- c)Coleta de dados: a coleta de dados na pesquisa-ação foi realizada diretamente por meio do preenchimento das matrizes da sistemática proposta, i.e., a sistemática funcionou como protocolo da pesquisa. Além disso, foram registradas as opiniões dos participantes durante a aplicação da sistemática. Esta etapa é descrita na seção 5 .

- d)Análise dos dados: foi realizada por meio dos próprios resultados obtidos na aplicação da sistemática, além da avaliação das percepções dos usuários da sistemática. Como resultado, identificaram-se pontos que precisavam ser ajustados, que são descritos na seção 5.2.

- e)Implementar ações: as ações consistiram no ajuste da sistemática e na nova aplicação e avaliação dos pontos mudados no caso prático. Esses detalhes são descritos na seção 5.2 .

- f)Avaliar resultado: a avaliação final dos resultados é apresentada na seção 5.2. Os resultados obtidos também foram contrastados com propostas da literatura, através de uma discussão apresentada na seção 6.

Por fim, é importante destacar que nas seções a seguir são apresentados apenas os resultados finais da sistemática obtida. Detalhes sobre os ajustes que foram necessários são descritos sucintamente na seção 4.2 .

\section{Sistemática de integração proposta}

A sistemática proposta neste artigo serve de apoio na avaliação dos componentes no desenvolvimento de novos produtos. Essa avaliação considera as características de qualidade, por meio do QFD, e as características de confiabilidade, por meio da FMEA. A utilização do QFD estabelece as prioridades para atender à qualidade demandada pelos clientes, enquanto a FMEA busca reduzir os riscos de falhas que afetariam a confiabilidade do produto. A abordagem proposta permite a integração dessas duas visões em um diagrama de decisão para a avaliação dos componentes a serem desenvolvidos.
Esse diagrama busca orientar a decisão sobre quais aspectos do produto devem ser priorizados durante o desenvolvimento, de acordo com a importância que têm para a qualidade e confiabilidade. Além disso, para a avaliação dos componentes do produto através do diagrama, propõe-se um índice de FMEA modificado que associa os riscos com critérios financeiros, tornando-o um indicador mais objetivo se comparado com a FMEA tradicional.

Para a construção teórica da sistemática foram seguidas as etapas metodológicas abordadas em trabalhos anteriores similares, tais como os de Frank et al. (2011) e Fernandes e Rebelato (2006). Assim como nesses trabalhos, a construção da sistemática proposta baseia-se primeiramente numa pesquisa bibliográfica, uma vez que outros métodos de integração anteriores foram analisados e serviram de inspiração para a presente proposta. Além disso, a proposta consiste num desenvolvimento teóricoconceitual baseado num processo de sistematização e organização do conhecimento sobre as atividades de tomada de decisão. Posteriormente, foi conduzida a pesquisa-ação para o ajuste da sistemática, conforme as etapas explicadas na seção 3 . A presente seção explica a sistemática final obtida por meio do processo iterativo de desenvolvimento e ajuste baseado na pesquisa-ação conduzida.

A sistemática proposta é composta por sete etapas (Figura 6) formadas por: (i) determinação dos índices de priorização da qualidade demandada $\left(\mathrm{ID}_{\mathrm{i}}\right)$, por meio de uma pesquisa junto ao público alvo; (ii) elaboração da matriz QFD da qualidade, em que são determinadas as especificações técnicas e os respectivos pesos (1Qj); (iii) elaboração da matriz do produto, em que são determinados os índices de priorização dos componentes do produto $\left(\mathrm{IP}_{\mathrm{i}}\right)$; (iv) determinação das possíveis falhas dos componentes, com as probabilidades das ocorrências $\left(\mathrm{O}_{\mathrm{ij}}\right)$ e de detecção delas $\left(\mathrm{D}_{\mathrm{ij}}\right)$; (v) avaliação dos custos associados à severidade da falha $\left(\mathrm{Cs}_{\mathrm{ij}}\right)$; (vi) elaboração da FMEA modificada e obtenção de um índice de risco financeiro do componente ( $\mathrm{Rc}_{\mathrm{i}}$ ); e (vii) construção do diagrama de decisão para o desenvolvimento dos componentes.

As três primeiras fases da sistemática consistem na aplicação tradicional do QFD e, portanto, não serão aprofundadas neste artigo, uma vez que esse tema já foi abordado em outros trabalhos (por exemplo: CHENG; MELO FILHO, 2007). As demais fases dessa sistemática serão detalhadas a seguir.

\subsection{Identificação da qualidade demandada}

De acordo com Miguel (2005) e Mehrjerdi (2010), o ponto de partida para a aplicação das matrizes do QFD é o levantamento da voz do cliente, de 


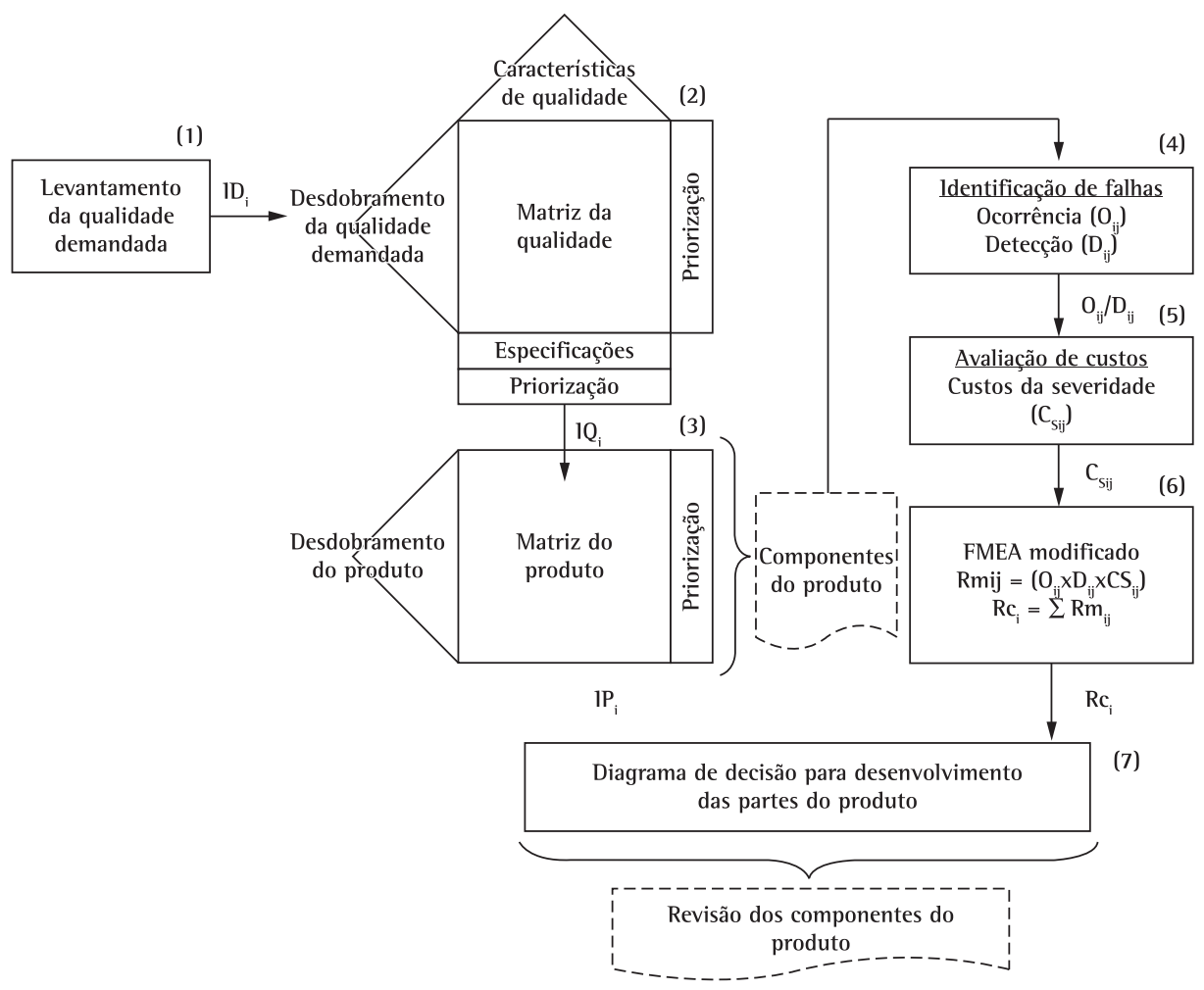

Figura 6. Sistemática para a integração do QFD e da FMEA na tomada de decisões do PDP.

acordo com suas necessidades. Essa etapa consiste na elaboração de uma pesquisa de mercado para levantar os itens da qualidade demandada pelos clientes. Primeiramente, recomendam-se pesquisas qualitativas como entrevistas individuais ou por meio de grupos focados que permitam identificar as necessidades e desejos dos clientes. Na sequência, desdobra-se a qualidade demandada de maneira hierárquica, formando o que é conhecido na literatura como "árvore da qualidade demandada", que organiza e define pontos específicos que atendam as demandas de qualidade. Finalmente, considerando os pontos identificados, aplica-se um questionário fechado por meio do qual são determinados os pesos de cada um dos aspectos da qualidade demandada ( $\left(\mathrm{D}_{\mathrm{i}}\right)$, mediante a avaliação dos clientes de cada um dos itens em uma escala de 1 (nada importante) a 10 (muito importante).

\subsection{Elaboração da matriz QFD da qualidade demandada}

Os pesos da qualidade demandada $\left(\mathrm{ID}_{\mathrm{i}}\right.$ ) obtidos na etapa anterior são utilizados na construção da matriz da qualidade demandada que aponta as características de qualidade mais relevantes no atendimento das necessidades do cliente (GOVERS, 1996; CHAN; WU, 2003; MEHRJERDI, 2010). Nessa matriz são avaliadas e preenchidas as relações $D_{i j}$ entre cada item de qualidade demandada e as características de qualidade que quantificam essa demanda. Para o preenchimento da matriz de qualidade realiza-se a seguinte pergunta: "Se a característica da qualidade X for mantida em níveis excelentes, estará assegurado o atendimento da qualidade demandada Y?" A atribuição das notas para os relacionamentos é feita por meio de uma escala logarítmica com os seguintes pontos: 0 (contribuição nula), 1 (contribuição baixa); 3 (contribuição moderada); 6 (contribuição forte); 9 (contribuição muito forte). Com essa escala logarítmica ressaltam-se as relações mais fortes (6 e 9) (FRANCESCHINI; RUPIL, 1999). Os pesos das características de qualidade $\left(\mathrm{IQ}_{\mathrm{j}}\right)$ são determinados mediante uma soma das relações entre as características de qualidade e as demandas da qualidade $\left(D^{i j}\right)$, ponderadas pelos pesos das qualidades demandadas (ID), conforme Equação 1.

$$
1 Q_{j}=\sum_{i=1}^{n} I D_{i} \times D Q_{i j}
$$

\subsection{Elaboração da matriz QFD do produto}

$\mathrm{Na}$ matriz do produto identificam-se os componentes do produto que devem atender às 
características de qualidade estabelecidas na matriz anterior (CHENG; MELO FILHO, 2007). A avaliação é realizada por meio do cruzamento entre cada componente do produto e as características de qualidade, buscando responder à seguinte pergunta: "Se o componente do produto $\mathrm{X}$ for excelente, estará atendida a característica de qualidade Y?" A partir do grau de relacionamento $\left(\mathrm{CQ}_{\mathrm{ij}}\right)$, atribuído pela equipe e ponderado pela importância de cada característica de qualidade resultante da matriz anterior $\left(1 Q_{j}\right)$, obtém-se a priorização dos componentes do produto $\left(\mathrm{IP}_{\mathrm{i}}\right)$, conforme Equação 2.

$$
I P_{i}=\sum_{i=1}^{n} 1 Q_{i} \times C Q_{i j}
$$

A priorização $\left(\mathrm{IP}_{\mathrm{i}}\right)$ determina quais componentes do produto são os mais importantes para atender aos itens da qualidade demandada. 0 desenvolvimento das duas matrizes do QFD auxilia no entendimento de quais componentes são críticos para o desenvolvimento de um novo produto. Além disso, o índice $\mathrm{IP}_{\mathrm{i}}$ é utilizado nas etapas posteriores da sistemática proposta, na etapa de construção do diagrama de apoio à tomada de decisões.

\subsection{Identificação das falhas do produto}

0 primeiro passo na construção da FMEA é a identificação de todos os possíveis modos de falha, juntamente com suas possiveis causas, mecanismos de controle e efeitos sobre o cliente. A definição dos modos de falha de um produto é realizada pela própria equipe de desenvolvimento do produto, baseada na experiência em projetos anteriores, análise de dados provenientes de assistência técnica em produtos similares, análise de pesquisa de mercado e análise das falhas de produtos provenientes da concorrência.

Uma vez determinados os modos de falha do produto, é necessário definir os índices de ocorrência $\left(\mathrm{O}_{\mathrm{ij}}\right)$ e de detecção de cada modo de falha $\left(\mathrm{D}_{\mathrm{ij}}\right)$. $\mathrm{Na}$ FMEA tradicional, esses índices são obtidos subjetivamente, através de uma conversão das probabilidades em índices de uma escala numérica de 1 a 10 (GILCHRIST, 1993; SHAHIN, 2004). Todavia, autores como Gilchrist (1993), Shahin (2004) e Ahsen (2008) criticam a relação não linear entre e a probabilidade de ocorrência e a detecção de determinada falha e os índices utilizados para representar tais probabilidades. Para solucionar esse problema, autores como Gilchrist (1993), Rhee e Ishii (2003) e Ahsen (2008) utilizam as reais probabilidades de ocorrência e detecção para construir os índices da FMEA. No presente trabalho, também serão utilizadas as probabilidades de ocorrência e detecção de cada modo de falha, as quais podem ser estimadas através de históricos de reclamações por parte dos clientes, simulações ou resultados de amostragens de produção de produtos similares. A utilização das probabilidades de ocorrência e detecção para cada modo de falha também permitirá a agregação dos índices obtidos na FMEA de todos os modos de falha de cada componente do produto em um único índice para esses componentes, conforme será apresentado adiante, no índice de risco financeiro do componente (Rc), na seção 4.6. Essa agregação não seria possível com a utilização dos índices de ocorrência e detecção tradicionais (escala 0 a 10), uma vez que eles não estão representados em uma escala contínua e linear.

\subsection{Avaliação do custo de severidade das falhas}

$\mathrm{Na}$ versão tradicional da FMEA, o terceiro índice utilizado é o índice de severidade da falha $\left(\mathrm{S}_{\mathrm{ij}}\right)$. Esse indice é geralmente avaliado em uma escala de severidade de 1 a 10, a partir da experiência dos engenheiros. Porém, várias críticas têm sido feitas quanto à subjetividade dessa avaliação (BARKAl, 1999) e ao fato de serem feitas pelos desenvolvedores do produto e não pelos próprios clientes (TAN, 2003; SHAHIN, 2004; BRAGLIA; FANTONI; FROSOLINI, 2007). Uma solução para esse problema foi proposta por Gilchrist (1993) e Ahsen (2008), que adotaram os custos das falhas como índices de severidade. Esses autores avaliaram a severidade em termos da soma dos custos de ocorrência externa dessa falha, custos de detecção (inspeção) e custos de descarte ou correção. Seguindo uma lógica similar à apresentada por Gilchrist (1993) e Ahsen (2008), nessa etapa do método avalia-se, em termos monetários, quanto custaria para a empresa a reparação ou substituição de uma parte do produto que apresente falhas. Para tanto, é necessário avaliar para cada falha a forma em que deveria ser reparada, determinando-se assim, por meio dos custos de inspeção, reparo e substituição, uma avaliação objetiva da sua severidade. Nesses custos inclui-se também o impacto financeiro que essa falha pode produzir sobre todo o sistema (custo de parada do sistema) e o custo, também, da eventual necessidade de reparação de outros componentes do sistema que tenham sido prejudicados por ela. Dessa maneira obtém-se o índice de custo da severidade $\left(\mathrm{Cs}_{\mathrm{ij}}\right)$ de cada falha $j$ do componente $i$ avaliado em unidades monetárias. 0 custo da falha pode consistir no reprocessamento da parte do produto, a reparação 
no local, a troca por uma nova parte ou, na pior das possibilidades, a troca por um novo produto inteiro. Essa análise é específica de cada tipo de produto e mercado consumidor.

\subsection{Elaboração da FMEA modificada}

Com a determinação das probabilidades de ocorrência $\left(\mathrm{O}_{\mathrm{ijj}}\right)$ e detecção $\left(\mathrm{D}_{\mathrm{ij}}\right)$ e o custo da severidade de falha $\left(\mathrm{Cs}_{\mathrm{ij}}\right)$, constrói-se a FMEA modificada (Figura 7). Essa FMEA é iniciada da maneira tradicional, descrevendo-se para cada componente $i$ os modos de falha $\left(M_{i j}\right)$ e os efeitos de falha sobre o cliente $\left(E_{i j}\right)$. A seguir determina-se o índice de risco financeiro de modo de falha $\mathrm{Rm}_{\mathrm{ij}}$ (equação 3), que representa o custo esperado de cada uma das falhas. Esse índice é diferente do índice de risco tradicional, que é avaliado por uma escala atribuída, geralmente, de forma subjetiva.

$\mathrm{Rm}_{\mathrm{ij}}=O_{\mathrm{ij}} \times D_{\mathrm{ij}} \times C s_{\mathrm{ij}}$

Uma vez determinados os índices $\mathrm{Rm}_{\mathrm{ij}}$, calcula-se 0 risco financeiro do componente $i\left(\mathrm{Rc}_{\mathrm{i}}\right)$, que representa a soma dos riscos financeiros de todos os $\mathrm{j}$ modos de falha do componente $i\left(\mathrm{Rm}_{\mathrm{ij}}\right)$, como apresentado na equação 4.

$$
\mathrm{Rc}_{\mathrm{i}}=\sum_{j=1}^{n} R m_{i j}
$$

0 índice Rc, obtido através da FMEA modificada, e o índice de priorização dos componentes $\mathrm{IP}_{\mathrm{i}}$, obtido através do QFD, são utilizados para a construção do diagrama de decisão para o desenvolvimento dos componentes.

\subsection{Diagrama de decisão para o desenvolvimento dos componentes do produto}

0 diagrama proposto permite que o tomador de decisões possa observar em um mesmo diagrama os critérios relacionados à qualidade demandada do produto, representada indiretamente através do indice de priorização dos componentes do produto (IP $\mathrm{P}_{\mathrm{i}}$, e os critérios relacionados à confiabilidade dos componentes do produto, representado pelo índice de risco financeiro do componente $\left(R_{\mathrm{i}}\right)$.

0 diagrama é desenhado a partir de dois eixos: levando-se em consideração a importância do componente para a qualidade demandada (resultado do QFD) e a importância do componente para a confiabilidade (proveniente da FMEA). Dessa maneira, o projetista poderá definir os quadrantes do diagrama, que posicionam o componente em relação à qualidade $\left(\mathrm{IP}_{\mathrm{i}}\right)$ e à confiabilidade $\left(\mathrm{Rc}_{\mathrm{i}}\right)$, como ilustra a Figura 8.

Como é possível observar na Figura 8, o diagrama de decisão é dividido em quatro quadrantes classificados de acordo com a importância para a qualidade e para a confiabilidade dos componentes: (i) componentes de baixa criticidade, que apresentam baixos valores de $\mathrm{IP}_{\mathrm{i}}$ e $\mathrm{Rc}_{\mathrm{i}}$; (ii) componentes críticos quanto à qualidade, definidos por alto índice $\mathrm{IP}_{\mathrm{i}} \mathrm{e}$ baixo índice $\mathrm{Rc}_{\mathrm{i}}$; (iii) componentes críticos quanto à confiabilidade, definidos por baixo índice $\mathrm{IP}_{i}$ e alto índice Rc; ; e (iv) componentes críticos em ambas as dimensões, definidos pelos dois índices com valores elevados.

A região de qualidade crítica indica que no desenvolvimento do componente deve-se atentar para os aspectos da qualidade demandada como, por exemplo, design, ergonomia e outras características

\begin{tabular}{|c|c|c|c|c|c|c|}
\hline $\begin{array}{c}\text { Componente do } \\
\text { produto }\end{array}$ & $\begin{array}{l}\text { Modo de } \\
\text { Falha } \\
\end{array}$ & $\begin{array}{c}\text { Efeito de falha sobre o } \\
\text { cliente }\end{array}$ & $\mathbf{O}_{\mathrm{ij}}$ & $\mathbf{D}_{\mathrm{ij}}$ & $\mathrm{Cs}_{\mathrm{ij}}$ & $\mathbf{R m}_{\mathrm{ij}}$ \\
\hline \multirow{3}{*}{ Componente 1} & $\mathrm{M}_{11}$ & $\mathrm{E}_{11}$ & $\mathrm{O}_{11}$ & $\mathrm{D}_{11}$ & $\mathrm{Cs}_{11}$ & $\mathrm{Rm}_{11}$ \\
\hline & $\ldots$ & $\ldots$ & $\ldots$ & $\ldots$ & $\ldots$ & $\ldots$ \\
\hline & $\mathrm{M}_{1 \mathrm{j}}$ & $\mathrm{E}_{1 \mathrm{j}}$ & $\mathrm{O}_{1 \mathrm{j}}$ & $\mathrm{D}_{\mathrm{lj}}$ & $\mathrm{C}_{\mathrm{sj}}$ & $\mathrm{Rm}_{\mathrm{lj}}$ \\
\hline \multicolumn{6}{|c|}{ Risco Financeiro do componente 1} & $\mathrm{Rc}_{1}$ \\
\hline \multirow{3}{*}{ Componente 2} & $\mathrm{M}_{21}$ & $\mathrm{E}_{21}$ & $\mathrm{O}_{21}$ & $\mathrm{D}_{21}$ & $\mathrm{Cs}_{21}$ & $\mathrm{Rm}_{21}$ \\
\hline & $\ldots$ & $\ldots$ & $\ldots$ & $\ldots$ & $\ldots$ & $\ldots$ \\
\hline & $\mathrm{M}_{2 \mathrm{j}}$ & $E_{2 j}$ & $\mathrm{O}_{2 \mathrm{j}}$ & $\mathrm{D}_{2 \mathrm{j}}$ & $\mathrm{C}_{2 \mathrm{j}}$ & $\mathrm{Rm}_{2 \mathrm{j}}$ \\
\hline \multicolumn{6}{|c|}{ Risco Financeiro do componente 2} & $\mathbf{R c}_{2}$ \\
\hline$\ldots$ & $\ldots$ & $\ldots$ & & $\ldots$ & $\ldots$ & $\ldots$ \\
\hline \multirow{3}{*}{$\begin{array}{c}\text { Componente } \\
\text { i }\end{array}$} & Mil & $\mathrm{E}_{\mathrm{i} 1}$ & $\mathrm{O}_{\mathrm{il}}$ & $\mathrm{D}_{\mathrm{il}}$ & $\mathrm{CS}_{\mathrm{Sil}}$ & $\mathrm{Rm}_{\mathrm{il}}$ \\
\hline & $\ldots$ & $\ldots$ & $\ldots$ & $\ldots$ & $\ldots$ & $\ldots$ \\
\hline & $\mathrm{M}_{\mathrm{ij}}$ & $\mathrm{E}_{\mathrm{ij}}$ & $\mathrm{O}_{\mathrm{ij}}$ & $\mathrm{D}_{\mathrm{ij}}$ & $\mathrm{C}_{\mathrm{ij}}$ & $\mathrm{Rm}_{\mathrm{ij}}$ \\
\hline \multicolumn{6}{|c|}{ Risco Financeiro do componente i } & $\mathbf{R c}_{\mathrm{i}}$ \\
\hline
\end{tabular}

Figura 7. Estrutura esquemática da FMEA proposta. 


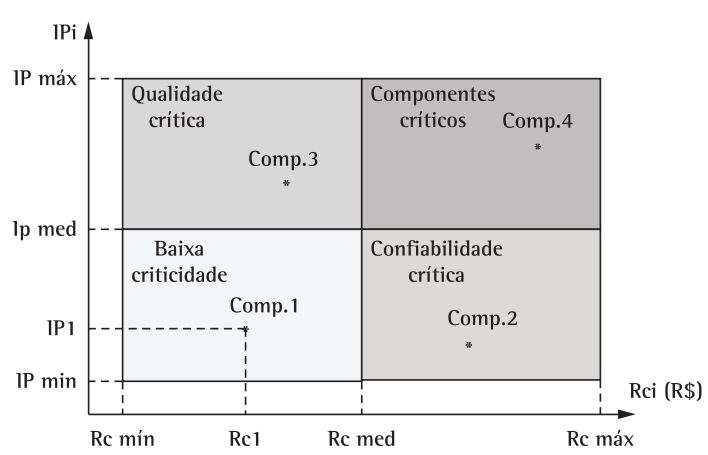

Figura 8. Diagrama de decisão para desenvolvimento dos componentes do produto

identificadas no QFD. A região de confiabilidade crítica indica que para esses componentes devem-se enfatizar os aspectos associados à confiabilidade através de testes de resistência, durabilidade e outras verificações de projeto. A região de componentes críticos delimita componentes que devem ser cuidadosamente projetados, já que esses apresentam os maiores valores nos índices de qualidade demandada e de confiabilidade. Finalmente, o quadrante de baixa criticidade reúne componentes de menor importância para o desenvolvimento do produto quando considerada a avaliação conjunta de qualidade e confiabilidade.

Para determinar os limites das regiões de baixa e alta criticidade podem ser utilizados a média ou a mediana dos valores $I P_{i}$ e $R c_{i}$, designados por $I P_{\text {med }}$ e $R c_{m e d^{\circ}}$ Nos casos em que existe um ponto muito afastado do conjunto de valores observados (por ex.: um componente com $\mathrm{IP}_{\mathrm{i}}$ e $\mathrm{Rc}_{\mathrm{i}}$ muito maior do que os demais), a média deixa de ser apropriada para delimitar os quadrantes, já que os demais componentes terão pouca influência na definição dos quadrantess, podendo ficar todos eles na zona de baixa criticidade. Nesses casos o valor da mediana pode ser uma melhor opção, por não ser afetado pelos pontos extremos. Contudo, se o número de componentes avaliados é impar, existirão componentes localizados sobre as linhas divisórias das regiões de baixa e alta criticidade. Caberá assim aos projetistas decidirem em qual das regiões esses componentes serão considerados.

\section{Avaliação prática da proposta}

Nesta seção é apresentada a aplicação prática do método proposto para o desenvolvimento dos componentes de um equipamento de ar condicionado. Para essa aplicação foi adotada uma pesquisa-ação conforme os passos apresentados na seção 3. A pesquisa-ação foi realizada junto a uma equipe de cinco engenheiros de produto de uma empresa multinacional que opera no Brasil há mais de 40 anos. Todos eles tinham conhecimento prévio sobre a utilização do QFD e da FMEA como ferramentas para o desenvolvimento de produtos. 0 QFD já era utilizada previamente nas rotinas da empresa, portanto foi possível utilizar informações de projetos anteriores para a construção das matrizes. Já a FMEA teve que ser completamente desenvolvida.

Os pesquisadores atuaram como orientadores da aplicação, explicitando inicialmente como a ferramenta deveria ser aplicada e, depois, acompanhando a construção das matrizes. Os passos metodológicos seguidos para a aplicação foram estruturados da seguinte maneira: (i) treinamento dos engenheiros sobre o método proposto; (ii) aplicação do QFD e da FMEA na empresa por parte dos engenheiros; (iii) revisão e ajuste dos resultados por parte dos pesquisadores; (iv) levantamento de dados adicionais por parte dos engenheiros; ( $v$ ) encerramento e conclusões (pesquisadores e engenheiros). 0 treinamento foi realizado na forma de aula, com uma duração de 8 horas.

\subsection{Resultados da aplicação}

Após o treinamento iniciou-se a fase de aplicação da sistemática na empresa. A aplicação foi realizada no desenvolvimento de uma linha de equipamentos de ar condicionado para aplicações comerciais de médio porte, como lojas e restaurantes. 0 primeiro passo foi o levantamento da qualidade demandada pelos clientes. A equipe de engenharia possuía informações sobre levantamentos passados que 0 setor de marketing e vendas tinha realizado com clientes e vendedores. Esses dados qualitativos sobre os critérios da qualidade demandada foram organizados e a equipe atribuiu pontuações às necessidades dos clientes. Dessa maneira obtiveram-se as notas $\mathrm{ID}_{\mathrm{i}}$ (ver Figura 9).

0 passo seguinte foi traduzir a qualidade demandada em características de qualidade que permitissem quantificar a demanda dos clientes. $\mathrm{Na}$ matriz da qualidade (Figura 9) apresentam-se, nas linhas, os requisitos da qualidade demandada, enquanto que nas colunas desdobram-se as especificações técnicas que permitem atender esses requisitos. Nas células de cruzamento entre as linhas e colunas avaliaram-se os graus de relacionamento entre cada aspecto da qualidade demandada e as características de qualidade (especificações técnicas). À direita das células de relacionamento têm-se os pesos $\mathrm{ID}_{\mathrm{i}}$ de cada uma das demandas de qualidade $i$ e, dessa forma, na última linha da mesma figura obteve-se como resultado os pesos $1 Q_{j}$ das características de qualidade $j$ que posteriormente foram utilizadas na matriz do produto. 


\begin{tabular}{|c|c|c|c|c|c|c|c|c|c|c|c|c|c|c|c|c|c|}
\hline $\begin{array}{c}\text { Matriz da Qualidade } \\
\text { Qualidade Demandada }\end{array}$ & 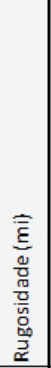 & ¿̀ & 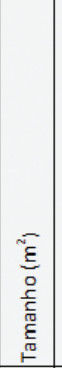 & $\begin{array}{l}\frac{0}{0} \\
\frac{0}{0} \\
\frac{0}{0} \\
\frac{0}{3}\end{array}$ & 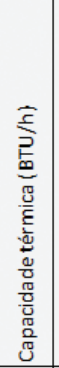 & 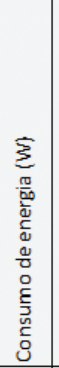 & 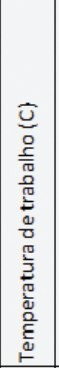 & 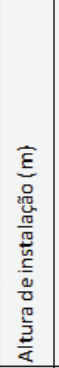 & 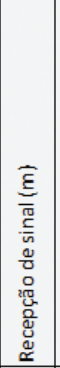 & 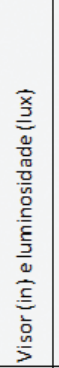 & 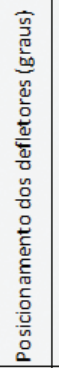 & 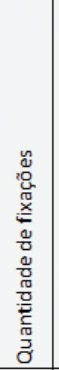 & 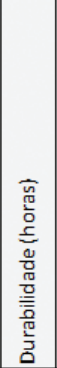 & 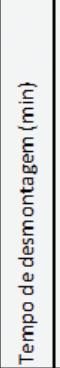 & 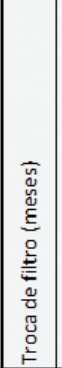 & 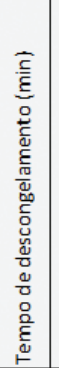 & IDi \\
\hline Acabamento & 9 & 9 & 3 & & & & & 1 & 1 & 3 & 1 & & 3 & & & & 4,41 \\
\hline Beleza - Aparência harmoniosa com ambiente & 9 & 9 & 9 & & & & & 1 & 1 & 3 & 3 & 1 & 3 & & & & 5,03 \\
\hline Tamanho reduzido & 1 & 1 & 9 & 3 & 3 & 3 & & 1 & & & & 1 & & 3 & & & 5,77 \\
\hline Isento de Ruído & & & & 9 & & & & 1 & & & & 3 & & & & & 9,78 \\
\hline Alta capacidade térmica & & & & & 9 & 9 & 3 & & & & 1 & & & & & 1 & 9,11 \\
\hline Baixo consumo de energia & & & 3 & & & 9 & 3 & & & 1 & & & & & 1 & 1 & 9,96 \\
\hline Versatilidade - Resfriamento/Aque cimento & & & & & 3 & & 9 & & & & & & & & & & 7,23 \\
\hline Manutenção da qualidade ao longo do te mpo & & & 1 & & & 6 & & 9 & 1 & 1 & 1 & & & 3 & 1 & & 6,68 \\
\hline Fácil regulagem a distância & & & & & & & & & 9 & & 1 & & & & & & 8,85 \\
\hline Fácil visualização da te mperatura & & & & & & & & & & 9 & & & & & & & 7,60 \\
\hline Fácil acesso as funções de comando & & & & & 1 & & 1 & & 1 & & 9 & & & & & & 8,43 \\
\hline Facilidade de instalação & & & 9 & & & & & 9 & & & & 9 & & 3 & & & 2,88 \\
\hline Durabilidade & & & & & & & & & & & & & 9 & 1 & 1 & & 4,04 \\
\hline Facilidade de manutenção & & & 1 & & & & & 6 & & & & 9 & 3 & 9 & 3 & & 3,84 \\
\hline Facilidade de limpeza & 3 & 3 & 1 & & & & 3 & 3 & & & & & & & 9 & & 3,50 \\
\hline Isento de congelamento & & & & & 9 & & & & & & & & 1 & & & 9 & 2,88 \\
\hline Especificações atuais & $\begin{array}{l}\bar{\varepsilon} \\
\stackrel{\tilde{m}}{\mathrm{v}} \\
\end{array}$ & & $\begin{array}{c}{ }^{n} \varepsilon \\
m \\
o \\
v \\
v\end{array}$ & $\begin{array}{l}0 \\
0 \\
\text { ก } \\
\square \\
v \\
\end{array}$ & $\begin{array}{l}? \\
\infty \\
\circ \\
\circ \\
\stackrel{\circ}{r} \\
\end{array}$ & $\begin{array}{l}3 \\
\vdots \\
\circ \\
\mathrm{r} \\
\mathrm{v} \\
\end{array}$ & $\begin{array}{l}0 \\
0 \\
0 \\
\infty \\
\infty \\
\infty \\
+\end{array}$ & $\begin{array}{c}\varepsilon \\
\text { m } \\
\mathrm{v}\end{array}$ & $\begin{array}{c}\varepsilon \\
\text { กิ } \\
\end{array}$ & $\begin{array}{l}\subseteq \\
N \\
v\end{array}$ & $\begin{array}{l}\text { นn } \\
\mathrm{v}\end{array}$ & $\nabla$ & 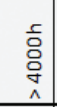 & 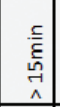 & 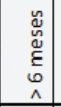 & $\begin{array}{c}c \\
\bar{\varepsilon} \\
m \\
v \\
\end{array}$ & \\
\hline Especificações meta & $\begin{array}{c}\bar{\varepsilon} \\
\circ \\
\vec{v} \\
\end{array}$ & & $\begin{array}{c}v \varepsilon \\
m \\
o \\
v\end{array}$ & $\begin{array}{l}\text { 尺̊ } \\
\text { กิ } \\
\text { v } \\
\end{array}$ & 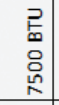 & $\begin{array}{l}3 \\
0 \\
0 \\
6 \\
v \\
\end{array}$ & $\begin{array}{c}0 \\
0 \\
0 \\
\pi \\
\infty \\
\infty \\
\sim \\
\end{array}$ & $\begin{array}{c}\varepsilon \\
m \\
v\end{array}$ & 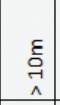 & $\stackrel{\subseteq}{\sim}$ & $\underset{\mathrm{v}}{\stackrel{\mathrm{q}}{\mathrm{g}}}$ & $\checkmark$ & 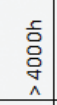 & $\begin{array}{c}\stackrel{c}{\varepsilon} \\
\stackrel{5}{\lrcorner} \\
\wedge \\
\wedge\end{array}$ & $\begin{array}{l}\stackrel{u}{a} \\
\stackrel{\omega}{\omega} \\
\varepsilon \\
\omega \\
\wedge\end{array}$ & $\begin{array}{c}\stackrel{c}{E} \\
m \\
v \\
\end{array}$ & \\
\hline $10 \mathrm{i}$ & 1,01 & 1,01 & 1,80 & 1,05 & 1,55 & 2,29 & 1,41 & 1,45 & 1,04 & 1,13 & 1,20 & 1,01 & 0,79 & 0,85 & 0,64 & 0,45 & \\
\hline
\end{tabular}

Figura 9. QFD: matriz da qualidade - ar-condicionado.

Uma vez elaborada a matriz da qualidade, partiu-se para o desdobramento da matriz do produto, na qual foram identificadas as partes do produto que atendem às características de qualidade especificadas. $\mathrm{Na}$ Figura 10 pode-se observar que as linhas da matriz do produto apresentam as diferentes partes do produto, enquanto as colunas, assim como na matriz da qualidade, apresentam as características de qualidade (especificações técnicas). Nas células de cruzamento entre as linhas e colunas avaliam-se os graus de relacionamento entre cada componente do produto e as características de qualidade.

Como resultado da matriz de produto, à direita das células de relacionamento obtêm-se os pesos de importância $\left(\mathrm{IP}_{\mathrm{i}}\right)$ de cada componente do produto, que foram utilizados posteriormente na construção da FMEA. Os pesos $\mathrm{IP}_{\mathrm{i}}$ obtidos na matriz do produto foram ilustrados em um gráfico em forma de Pareto (Figura 11). Nesse gráfico identificou-se a hierarquia entre os componentes, considerando sua influência no atendimento das características de qualidade.

A seguir elaborou-se a FMEA apresentada na Figura 12. As probabilidades do índice de ocorrência das falhas $\left(\mathrm{O}_{\mathrm{ij}}\right)$ foram estabelecidas em relação aos problemas mais habituais observados nesse tipo de produto. Os índices de detecção das falhas $\left(D_{\mathrm{ij}}\right)$ foram estabelecidos considerando a dificuldade técnica em detectar a possível falha durante o desenvolvimento do produto. Isso significa que as probabilidades para ambos os índices foram estabelecidas em relação à experiência dos técnicos e os históricos que a empresa tem de falhas no passado.

Para a avaliação do índice de custos de severidade das falhas $\left(\mathrm{Cs}_{\mathrm{ij}}\right)$, foi considerado o valor da peça a ser trocada para que o produto volte ao seu funcionamento normal. Por exemplo, no caso da plataforma e painel frontal (Figura 12), o custo de reparação da falha de vazamento é menor do que a falha por quebra, uma vez que esse último envolve a troca da estrutura completa, enquanto que o primeiro considera apenas a troca das vedações. 0 custo de assistência técnica para a reparação não foi incluído, pois é um valor fixo que não depende do tipo de peça a ser trocada. No caso analisado não foi considerado o custo do tempo de parada do equipamento, uma vez que já está previsto na garantia do produto a possibilidade de assistência técnica e reparação num prazo máximo de 10 dias. 
Uma vez obtidos os índices $\mathrm{O}_{\mathrm{ij}}$, $\mathrm{D}_{\mathrm{ij}}$ e $\mathrm{Cs}_{\mathrm{ij}}$, calculou-se o risco financeiro de modo de falha $\left(\mathrm{Rm}_{\mathrm{ij}}\right)$ e o risco financeiro do componente $\left(\mathrm{Rc}_{\mathrm{i}}\right)$. Os resultados dos índices $\mathrm{Rc}_{\mathrm{i}}$, ilustrados no gráfico de Pareto da Figura 13, foram posteriormente utilizados no diagrama de decisão.

Com os índices de qualidade (IP) e de confiabilidade $\left(\mathrm{Rc}_{\mathrm{i}}\right)$, procedeu-se à construção do diagrama de decisão

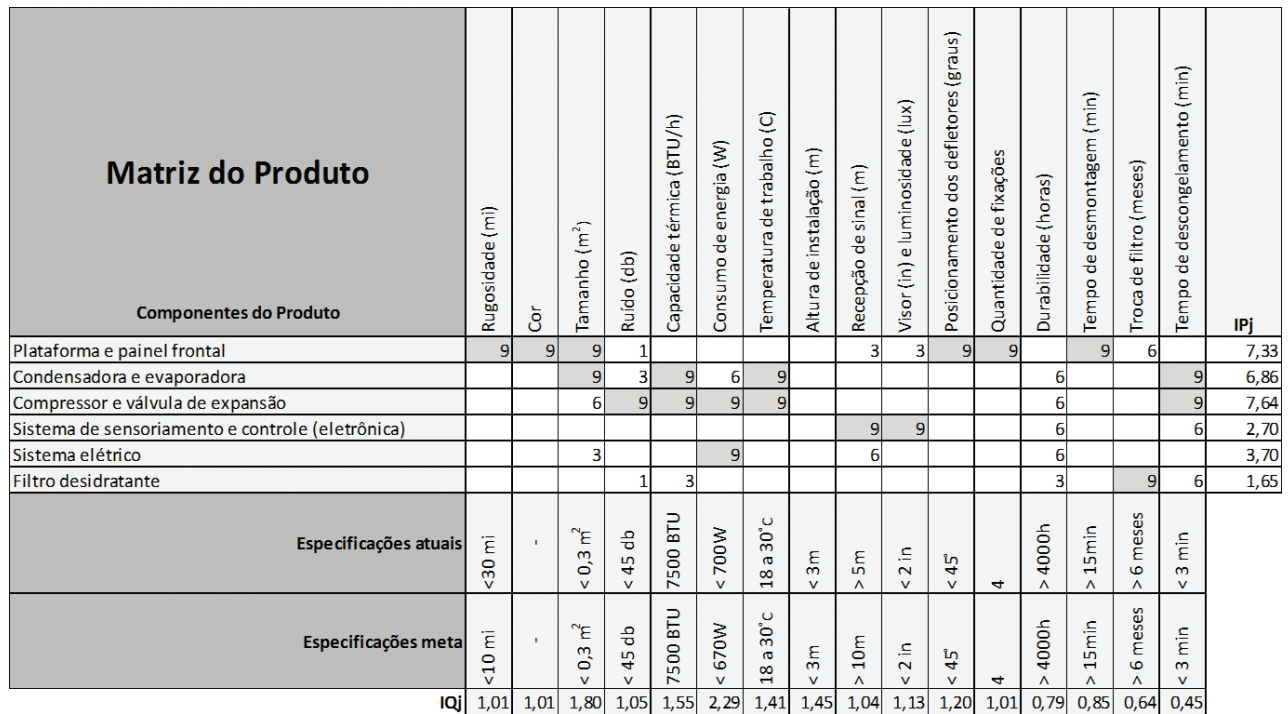

Figura 10. QFD: matriz do produto - ar-condicionado.

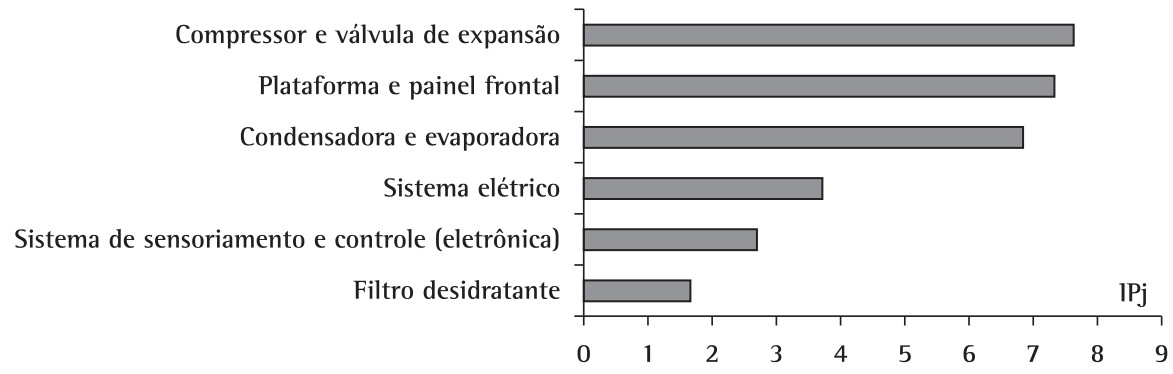

Figura 11. Priorizações $\left(\mathrm{IP}_{\mathrm{i}}\right)$ das partes do produto.

\begin{tabular}{|c|c|c|c|c|c|c|c|c|}
\hline Componente & Modo Potencial de Falha & Efeito Potencial de Falha & Causa & Oij & $\mathrm{Dij}_{\mathrm{ij}}$ & Csij & & imij \\
\hline \multirow{4}{*}{\begin{tabular}{l|} 
Plataforma e panel \\
frontal
\end{tabular}} & Vazamento & Operação intermitente & Vedações inadequadas & 0,0010 & 0,4 & $\mathrm{R} \$ 100,00$ & $\mathrm{RS}$ & 0,040 \\
\hline & Vazamento & Operação intermitente & Contaminação do óleo hidráulico & 0,0100 & 0,5 & $R \$ 50,00$ & RS & 0,250 \\
\hline & Afrouxamento & Ruído & Torque insuficiente & 0,0200 & 0,5 & $R \$ 200,00$ & RS & 2,000 \\
\hline & & & & & & Rci & RS & 2,29 \\
\hline \multirow{2}{*}{$\begin{array}{l}\text { Condensadora e } \\
\text { evaporadora }\end{array}$} & Perfuração & Baixo rendimento/ Descontinuidade de operação & Presença de corroção na superfície & 0,0020 & 0,6 & $R \$ 120,00$ & RS & 0,144 \\
\hline & & & & & & Rci & $\mathbf{R S}$ & 1,27 \\
\hline \multirow{5}{*}{ Compressor } & Ineficiencia têrmica & Incapacidade de refrigerar o ambiente & Dimensionamento inadequado & 0,0005 & 0,1 & $R \$ 550,00$ & RS & 0,028 \\
\hline & Ineficiencia têrmica & Incapacidade de refrigerar o ambiente & Problema do material & 0,0005 & 0,2 & $R \$ 550,00$ & RS & 0,055 \\
\hline & Ineficiencia têrmica & Incapacidade de refrigerar o ambiente & Especificação incorreta do material & 0,0005 & 0,1 & $R \$ 550,00$ & RS & 0,028 \\
\hline & Vazamento & Baixo rendimento & Vedações inadequadas & 0,0010 & 0,4 & $R \$ 70,00$ & $\mathrm{RS}$ & 0,028 \\
\hline & & & & & & Rci & RS & 0,14 \\
\hline $\begin{array}{l}\text { Válvula de expansão } \\
\text { termostática }\end{array}$ & Bloqueio & Ineficiência do circuito & Elementos estranhos ou gelo & 0,0100 & 0,6 & RS 70,00 & RS & 0,420 \\
\hline & & & & & & Roi & RS & 0,32 \\
\hline \multirow{4}{*}{ Filtro desidratante } & Obstrução & Preexpanção e perda da eficacia do circuito & Desgaste e saturação do filtro & 0,0200 & 0,8 & $\operatorname{RS} 60,00$ & RS & 0,960 \\
\hline & Ineficiencia de filtragem & Corroção por excesso de humidade no circuito & Dimensionamento inadequado & 0,00050 & 0,1 & $R \$ 60,00$ & RS & 0,003 \\
\hline & Ineficiencia de filtragem & Corroção por excesso de humidade no circuito & Especificação incorreta do material & 0,00050 & 0,1 & $R \$ 60,00$ & RS & 0,003 \\
\hline & & & & & & Ri & RS & 0,97 \\
\hline
\end{tabular}

Figura 12. FMEA modificada para a avaliação dos índices de confiabilidade do ar-condicionado. 
para o desenvolvimento dos componentes, conforme apresentado na Figura 14.

Para estabelecer as regiões do diagrama, foram utilizados os valores médios de $\mathrm{IP}_{i}$ e Rc, obtendo-se os seguintes limites das regiões: $I P_{\text {med }}=5,36 \mathrm{e}$ $R c_{\text {med }}=R \$ 0,88$. No diagrama é possível observar que os resultados dos índices de importância assinalam dois componentes críticos: "condensador e evaporadora”, que compõem um único sistema, e "plataforma e painel frontal", que compõem outro sistema. Por outro lado, o filtro hidratante possui uma alta importância para o atendimento da confiabilidade, mas não é considerado crítico para os aspectos da qualidade. Já o compressor e a válvula de expansão são muito importantes para o atendimento da qualidade demandada, mas não para o atendimento da confiabilidade. Os sistemas "elétrico" e de "sensoriamento e controle" são importantes para a funcionalidade do produto, mas não são essenciais para atender aos atributos de qualidade demandada e confiabilidade que impactam no cliente.

Dessa maneira, o diagrama de decisão sintetizou as informações sobre qualidade e confiabilidade do produto, permitindo determinar os parâmetros críticos do ar-condicionado a ser desenvolvido. A partir disso, os resultados permitiram revisar o projeto dos componentes do produto proposto, realizando os ajustes necessários para priorizar os parâmetros críticos de cada componente.

\subsection{Considerações sobre a aplicação no caso prático}

Ressalta-se que os resultados anteriormente apresentados foram obtidos com a aplicação da versão final da sistemática. Durante a pesquisa-ação foram necessários alguns ajustes da sistemática, dentre eles: (i) as etapas do QFD foram simplificadas, uma vez que a versão original possuía outros índices propostos por Ribeiro, Echeveste e Danilevicz (2007), tais como a avaliação estratégica e competitiva das características da qualidade - esses índices tornavam a avaliação complexa e sua contribuição marginal não foi considerada justificável na sistemática proposta; e (ii) a criticidade da falha na FMEA da sistemática original era a utilizada no processo tradicional da FMEA. $\mathrm{Na}$ discussão prática identificou-se a oportunidade de adicionar o custo de severidade de falha na versão final da sistemática.

Por outro lado, a respeito da aplicabilidade da sistemática proposta, no presente caso observou-se

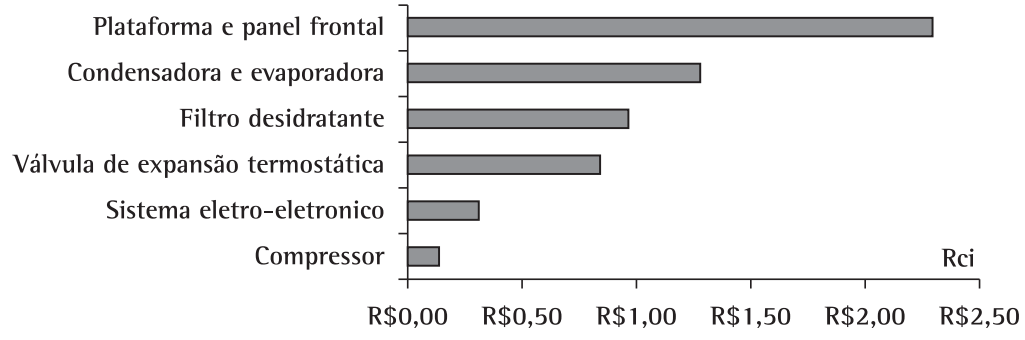

Figura 13. Gráfico de Pareto dos índices $R c_{\mathrm{i}}$ do ar-condicionado.

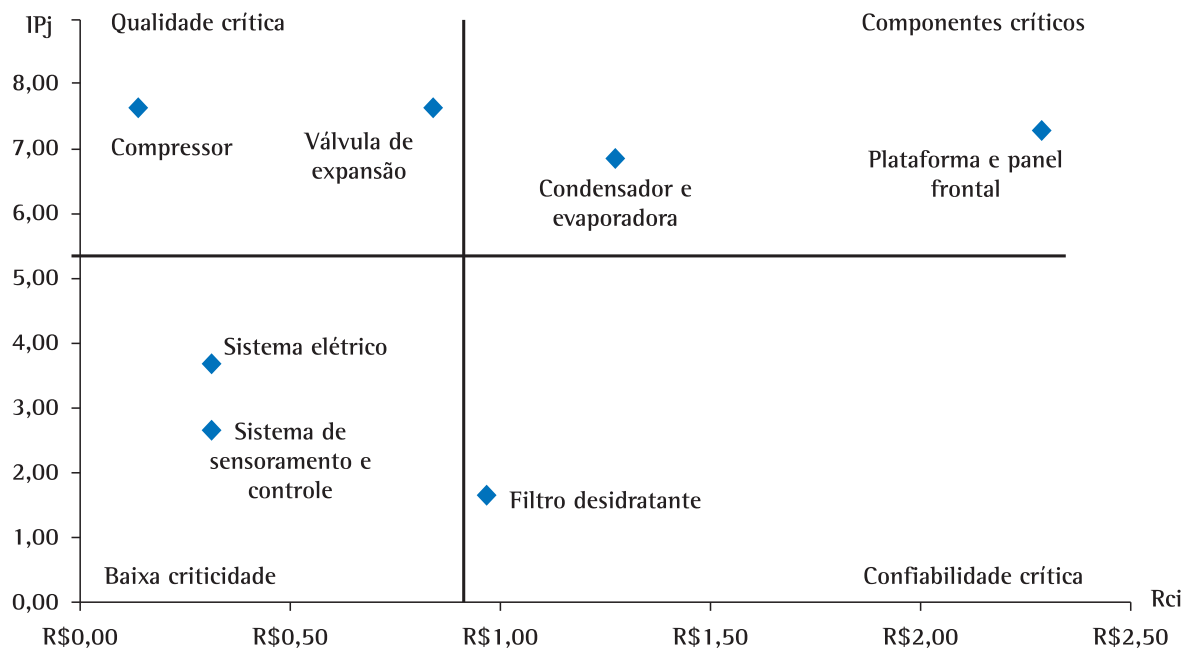

Figura 14. Diagrama de decisão para o desenvolvimento dos componentes do ar-condicionado. 
certa facilidade de utilização. Possivelmente, isso ocorreu porque a equipe possuía conhecimentos prévios sobre QFD e FMEA, além de a aplicação ter sido orientada pelos pesquisadores. A maior dificuldade observada, tanto nesta como em outras aplicações realizadas, é a de desdobrar corretamente as matrizes do QFD, principalmente no que tange à relação entre a qualidade demandada e as especificações técnicas da matriz da qualidade. Por outro lado, não foram observadas dificuldades na avaliação de aspectos técnicos do produto, tais como o relacionamento das especificações técnicas com os componentes de produtos (matriz do produto) e a definição de falhas, dos respectivos custos e das probabilidades de ocorrência e detecção.

Também deve ser ressaltado que a aplicação demanda um considerável tempo de envolvimento das equipes, pois o QFD e a FMEA são ferramentas que requerem discussão entre os participantes para o preenchimento das matrizes. Portanto, cabe aos líderes de desenvolvimento de produto avaliar em quais produtos vale a pena investir o tempo necessário para uma aplicação desse tipo.

\section{Discussões}

Na revisão da literatura foram apresentados outros trabalhos anteriores que propuseram alguma forma de integração entre o QFD e a FMEA. No método de Cheng e Melo Filho (2007) e Tanik (2010), a integração acontece em uma perspectiva de sistematização da utilização das ferramentas, sendo organizada como passos sucessivos, analisando através da FMEA os componentes prioritários obtidos do QFD. No obstante, os componentes definidos como prioritários no QFD podem não ser os mais importantes para a análise da FMEA. Isso ocorre porque o QFD é apoiada na voz do cliente, o que permite identificar com precisão aquilo que satisfaz o cliente, mas pode não capturar a importância de aspectos técnicos associados à segurança de operação, resistência e durabilidade, que deveriam ser analisados na FMEA. Em contrapartida, a sistemática proposta analisa na FMEA todos os componentes priorizados no QFD para assim comparar os resultados de ambas as ferramentas no gráfico de decisão, o qual permitirá estabelecer quais dos aspectos - confiabilidade ou qualidade - é prioritário para cada um dos componentes do produto. Nesse caso existe a desvantagem de ser necessária a análise de um número maior de componentes na FMEA, mas isso garante que seja considerada uma maior quantidade de aspectos técnicos do produto na análise de confiabilidade. Além disso, o fato de o projetista utilizar um diagrama para a tomada de decisão final faz com que seja mais fácil observar os relacionamentos e importâncias entre a qualidade e a confiabilidade dos componentes.
Por outro lado, no método proposto por Fernandes e Rebelato (2006) e Frank, Pedrini e Echeveste (2008), a ênfase é dada à integração das duas ferramentas por meio dos índices resultantes delas. De acordo com a proposta de Fernandes e Rebelato (2006), os valores obtidos das priorizações dos componentes no QFD (IP ${ }_{j}$ ) são transportados para a FMEA e considerados como representativos da severidade da falha $\left(\mathrm{S}_{\mathrm{ij}}\right)$. Por outro lado, Frank, Pedrini e Echeveste (2008) sugeriram um índice de risco modificado, que é obtido pela multiplicação do índice de risco padronizado da FMEA pelo índice de priorização dos componentes padronizado (IP), obtido no QFD. Porém algumas vezes ambas as considerações não representam corretamente o que acontece na prática. Por exemplo, por questões técnicas, a falha de um item de segurança pode ter um efeito muito severo, mas o cliente pode não enxergar os efeitos dessa falha (TAN, 2003). Além disso, Fernandes e Rebelato (2006) consideram que todas as falhas de um componente têm a mesma severidade, dada pelo índice de priorização do componente analisado (IP). Contudo, isto não acontece necessariamente em todos os casos práticos. Por exemplo, um determinado componente pode correr o risco de sofrer diferentes falhas, sendo algumas muito severas, que comprometem toda a sua utilidade, enquanto outras podem ser falhas menores, que comprometem apenas alguma funcionalidade desse componente. Por conseguinte, o método apresentado neste trabalho busca preencher essas lacunas por meio da utilização de índices independentes entre as ferramentas propostas, os quais são comparados somente no final, por meio do diagrama de decisão. Além disso, o método proposto considera a possibilidade de analisar várias falhas para cada componente, com diferentes índices de severidade associados a cada falha, o que permite uma análise mais completa dos modos de falha.

Outra vantagem da proposta deste artigo é a inclusão, na análise da FMEA, de um índice que avalia, além dos modos de falha individuais para os componentes, também o risco geral associado a cada componente, levando em consideração todas as possíveis falhas associadas a ele. Os índices de ocorrência e detecção das falhas do produto são estabelecidos probabilisticamente, enquanto o índice de severidade da falha é avaliado em valores monetários. Dessa maneira, o índice de risco obtido na FMEA modificada traduz o custo associado aos modos de falha dos diferentes componentes e é utilizado para a tomada de decisões no diagrama proposto. Isso representa um avanço em relação ao que foi proposto por Gilchrist (1993) e Ahsen (2008), que sugeriram o uso de indicadores quantitativos em forma de custos das falhas. Assim sendo, a presente proposta acrescenta a essas abordagens a estimativa do custo total de cada componente. 


\section{Considerações finais}

A contribuição principal deste trabalho reside na proposta de uma sistemática que integra a utilização de QFD e FMEA no processo de desenvolvimento de produtos por meio de um diagrama de apoio à tomada de decisões. Com esse diagrama é possível identificar os principais componentes do produto a serem priorizados para atender os requisitos de qualidade e confiabilidade.

Também se destaca que o emprego dessas ferramentas permite o compartilhamento do conhecimento da equipe de desenvolvimento, pois integra as visões de planejamento da qualidade, geralmente lideradas por marketing e alta gerência, à visão de prevenção de falhas, geralmente liderada por engenharia de produto e processo. Dessa maneira, por meio da sistemática de integração sugerida, ambas as áreas são representadas no diagrama proposto, facilitando as decisões e solução de trade-offs usualmente presentes no processo de desenvolvimento do produto.

Os resultados da aplicação prática destacaram a contribuição da sistemática e sua fácil utilização pela equipe de engenharia de produto. Contudo, uma limitação que apresenta este trabalho é que a sistemática foi ajustada por meio de um único caso prático. Assim sendo, as conclusões sobre os resultados práticos não são generalizáveis. Portanto, uma oportunidade para futuras pesquisas consiste na aplicação da proposta num número maior de empresas, comparando os resultados delas. Sugere-se que sejam avaliados casos de diferentes tipos de produtos para assim testar a abrangência da utilidade da sistemática desenvolvida.

Outra limitação é que a sistemática proposta não avalia diretamente a dependência entre os componentes. Cálculos de confiabilidade considerando dependência entre os elementos são um assunto complexo que exige modelagem específica para cada caso e fogem ao escopo deste trabalho. A FMEA e o QFD são ferramentas mais simples e, exatamente por essa simplicidade, passíveis de uso mais amplo na indústria. No entanto, indiretamente, os índices da FMEA contemplam casos mais sérios de dependência, que podem ser penalizados através da estimação do custo da severidade da falha para o sistema. Recomenda-se que trabalhos futuros contemplem esse aspecto no cálculo da confiabilidade.

Finalmente, cabe ressaltar que a sistemática de integração proposta enfatiza o desenvolvimento dos componentes do produto. Porém, ela poderia igualmente ser utilizada em aplicações da matriz QFD de processos, onde também podem ser realizadas avaliações de FMEA (de processo, nesse caso). Uma possivel frente de pesquisa a ser empreendida pode estudar a replicação dessa sistemática em outras fases do PDP. Além disso, existem alguns tipos de produtos, como aqueles que não têm partes e são desenvolvidos por meio de processos (por exemplo: cimento, alimentos, celulose etc.), nos quais a aplicação da sistemática proposta pode necessitar de adaptações.

\section{Referências}

AHSEN, A. V. Cost-oriented failure mode and effects analysis. International Journal of Quality and Reliability Management, v. 25, n. 5, p. 466-476, 2008. http://dx.doi. org/10.1108/02656710810873871

AKAO, Y. Quality Function Deployment: Integrating Customer Requirements into Product Design. Cambridge: Productivity Press, 1988.

BARKAl, J. Automatic generation of a diagnostic expert system for failure mode and effects analysis (FMEA) information. In: SAE International Congress and exposition, 1999, Detrioit. Proceedings... Warrendale: SAE, 1999.

BRAGLIA, M.; FANTONI, G.; FROSOLINI, M. The house of reliability. International Journal of Quality and Reliability Management, v. 24, n. 4, p. 420-440, 2007. http://dx.doi. org/10.1108/02656710710740572

BOSCH, V. G.; ENRÍQUEZ, F. T. TQM and QFD: exploiting a customer complaint management system. International Journal of Quality \& Reliability Management, v. 22, n. 1, p. 30-37, 2005. http://dx.doi. org/10.1108/02656710510572977

CARNEVALLI, J. A.; MIGUEL, P. A. C. Revisão, análise e classificação da literatura sobre o QFD - tipos de pesquisa, dificuldades de uso e benefícios do método. Gestão \& Produção, v. 14, n. 3, p. 557-579, 2007. http://dx.doi. org/10.1590/S0104-530X2007000300011

CARNEVAlll, J. A.; SASSI, A. C.; MIGUEL, P. A. C. Aplicação do QFD no desenvolvimento de produtos: levantamento sobre seu uso e perspectivas para pesquisas futuras. Gestão \& Produção, v. 11, n. 1, p. 33-49, 2004. http://dx.doi. org/10.1590/S0104-530X2004000100004

CHAN, L.; WU, M. Quality function deployment: a comprehensive review of its concepts and methods. Quality Engineering, v. 15, n. 1, p. 23-35. 2003.

CHENG, L. C.; MELO FILHO, L. D. R. QFD - Desdobramento da Função Qualidade na Gestão de Desenvolvimento de Produtos. São Paulo: Editora Blücher, 2007.

DIKMEN, 1.; BIRGONUL, M. T.; KIZILTAS, S. Strategic use of quality function deployment (QFD) in the construction industry. Building and Environment, v. 40 , p. $245-255$, 2005. http://dx.doi.org/10.1016/j. buildenv.2004.07.001

FERNANDES, J. M. R.; REBElATO, M. G. Proposta de um método para integração entre QFD e FMEA. Revista Gestão \& Produção, v. 13, n. 2, p. 245-259, 2006. http://dx.doi. org/10.1590/S0104-530X2006000200007

FRANCESCHINI, F.; GALETTO, M. A new approach for evaluation of risk priorities of failure modes in FMEA International Journal of Production Research, v. 39, n. 13, p. 2991-3002, 2001.

FRANCESCHINI, F.; RUPIL, A. Rating scales and prioritization in QFD. International Journal of Quality \& Reliability Management, v. 16, n. 1, p. 85-97, 1999.

FRANK, A. G.; PEDRINI, D. C.; ECHEVESTE, M. E. Integração das visões de QFD e FMEA por meio de um índice de falhas modificado. In: ENCONTRO NACIONAL DE ENGENHERIA DE PRODUÇÃO (ENEGEP), 18., 2008, Rio de Janeiro. Anais... Rio de Janeiro: Abepro, 2008. 
FRANK, A. G. et al. Sistemática de avaliação multicriterial de investimentos no desenvolvimento do produto. Produção, v. 21 , n. 4, p. 570-582, 2011. http://dx.doi.org/10.1590/ S0103-65132011005000060

GILCHRIST, W. Modelling Failure Modes and Effects Analysis. International Journal of Quality and Reliability Management, v. 10, n. 5, p. 16-23, 1993. http://dx.doi. org/10.1108/02656719310040105

GINN, D. M. et al. The QFD/FMEA interface. European Journal of Innovation Management, v. 1, n. 1, p. 7-20, 1998.

GOVERS, C. P. M. What and how about quality function deployment (QFD). International Journal of Production Economics, v. 46-47, p. 575-585, 1996.

KILLEN, C. P.; WALKER, M.; HUNT, R. A. Strategic planning using QFD. International Journal of Quality \& Reliability Management, v. 22, n. 1, p. 17-29, 2005. http://dx.doi. org/10.1108/02656710510572968

LEPREVOST, J.; MAZUR, G. Quality infrastructure improvement: QFD to manage project priorities and project management resources. International Journal of Quality \& Reliability Management, v. 22, n. 1, p. 10-16, 2005.

MARSOT, J. QFD: a methodological tool for integration of ergonomics at the design stage. Applied Ergonomics, v. 36, p. 185-192, 2005. http://dx.doi.org/10.1016/j. apergo.2004.10.005

MEHRJERDI, Y. Z. Quality function deployment and its extensions. International Journal of Quality and Reliability Management, v. 27, n. 6, p. 616-640, 2010. http://dx.doi. org/10.1108/02656711011054524

MELlO, C. H. P. et al. Pesquisa-ação na engenharia de produção: proposta de estruturação para sua condução. Produção, v. 22, n. 1, p. 1-13, 2012. http://dx.doi. org/10.1590/S0103-65132011005000056

MIGUEL, P. A. C. Evidence of QFD Best practices for product development: a multiple case study. International Journal of Quality and Reliability Management, v. 22, n. 1, p. 7282, 2005. http://dx.doi.org/10.1108/02656710510573002

PICKARD, K.; DIETER, A. Integrative qualitative quality assurance prediction over the complete product design cycle. Quality and Reliability Engineering International, v. 24 , n. 8, p. 903-910, 2008. http://dx.doi.org/10.1002/ qre.970
PUENTE, J. et al. A decision support system for applying failure mode and effects analysis. International Journal of Quality and Reliability Management, v. 19, n. 2, p. 137-150, 2001. http://dx.doi.org/10.1108/02656710210413480

RHEE, S. J.; 1SHIl, K. Using cost based FMEA to enhance reliability and serviceability. Advanced Engineering Informatics, v. 17, n. 3-4, p. 179-188, 2003. http://dx.doi. org/10.1016/j.aei.2004.07.002

RIBEIRO, J. L. D.; ECHEVESTE, M. E.; DANILEVICZ, A. M. A utilização do QFD no otimização de produtos, processos e serviços. Porto Alegre: FEENG/UFRGS, 2001. (Série Monográfica Qualidade).

ROSA, C. Practical Application of FMEA and QFD to Improve Product Quality. SAE, 2005. Technical Paper 2005-013972.

SHAHIN, A. Integration of FMEA and the Kano model: An exploratory examination. International Journal of Quality and Reliability Management, v. 21, n. 7, p. 731-746, 2004. http://dx.doi.org/10.1108/02656710410549082

TAN, C. M. Customer-focused build-in reliability: a case study. International Journal of Quality and Reliability Management, v. 20, n. 3, p. 378-397, 2003. http://dx.doi. org/10.1108/02656710310468560

TANIK, M. Improving “order handling” process by using QFD and FMEA methodologies: a case study. International Journal of Quality and Reliability Management, v. 27, n. 4, p. 404423, 2010. http://dx.doi.org/11.1108/02656711011035110

THIOLLENT, M. Metodologia de pesquisa-ação. 15. ed. São Paulo: Cortez, 2007.

VAN DE VEN, A. H. Engaged scholarship: a guide for organizational and social research. New York: Oxford, 2007.

YANG, K.; KAPUR, K. C. Customer driven reliability: integration of QFD and robust design. IEEE Proceedings of Annual Reliability and Maintainability Symposium, p. 339345, 1997. http://dx.doi.org/10.1109/RAMS.1997.571730

\section{Agradecimentos}

Os autores agradecem ao CNPq e à CAPES pelo apoio financeiro recebido através de bolsas de pesquisas.

\title{
A systematic of QFD and FMEA integration for decision-making in the product development process
}

\begin{abstract}
This paper presents a decision-making systematic that orients development actions during new product development (NPD). The systematic integrates QFD (Quality Function Deployment) and FMEA (Failure Mode and Effect Analysis), helping designers to determine which quality and reliability characteristics are most important in product parts development. The systematic was created by an action-research study conducted in partnership with a company that develops air conditioning equipment. The proposed systematic provides two key contributions: (i) a modification on the evaluation of FMEA risk measures, reducing their inherent subjectivity, and (ii) the integration of these measures with parts prioritization indices from QFD matrices, providing a decision diagram for parts development. This diagram allows one to visualize the impact of each part on quality and reliability characteristics, thus aiding in the decision process concerning the essential aspects for product development. The practical results highlight the ease of applying of this method, primarily in teams with a previous knowledge of QFD and FMEA.
\end{abstract}

\section{Keywords}

QFD. FMEA. Quality. Reliability. Product development. 